\title{
PREDICTION OF SEDIMENT DISASTERS DUE TO SHORT-DURATION HEAVY RAIN IN MOUNTAINOUS AREAS BASED ON REAL-TIME RAINFALL OBSERVATIONS
}

\author{
TAKEYASU SUZUKI ${ }^{1} \&$ TAKUMI ITO ${ }^{2}$ \\ ${ }^{1}$ Disaster and Environmentally Sustainable Administration Research Center, University of Yamanashi, Japan \\ ${ }^{2}$ Integrated Graduate School of Medicine, Engineering and Agricultural Sciences, University of Yamanashi, Japan
}

\begin{abstract}
Owing to the global abnormal weather in recent years, short-duration heavy rain that reaches $1,000 \mathrm{~mm}$ in $24 \mathrm{~h}$ occurs locally, causing large-scale sediment disasters and flooding of rivers in mountainous areas. To help in eliminating casualties caused by natural disasters, sediment disaster alert information has been issued since 2001 based on physical modelling with an input of analyzed precipitation derived by correcting precipitation radar data with ground rainfall observations. However, in mountainous areas where sediment disasters occur, precipitation may differ greatly from the analyzed rainfall depending on the location. Therefore, we placed real-time weather sensors in sediment disaster hazard zones and predicted the occurrence of sediment disasters based on actual local rainfall observational data for the purpose of issuing evacuation information. The authors used real-time rainfall observation for measuring rainfall intensity every minute in Nishikatsura Town, which is located in Yamanashi Prefecture at the foot of Mount Fuji. Through observation, it was revealed that there was a periodic pattern of rainfall-intensity variation during short-duration heavy rainfall. The authors took into consideration this variation pattern to develop a new method of predicting rainfall at that local site by combining real-time rainfall-observation results on record for the site with corresponding data from other sites. Using this real-time precipitation prediction, it is also possible to predict the occurrence of real-time sediment disaster. In this paper, the method of analyzing the variation pattern of rainfall intensity using real-time precipitation observation data is shown, and the validity of the prediction method is verified by performing rainfall prediction for a certain observation point using rainfallobservation data from another point.
\end{abstract}

Keywords: real-time, rainfall observation, heavy rain, prediction, simulation, sediment disaster.

\section{INTRODUCTION}

The abnormal weather caused by global warming has brought about torrential rain that has never been experienced before, causing heavy rain-related disasters in various parts of Japan. The 2017 Northern Kyushu heavy-rain disaster caused 42 casualties (40 dead and two missing), and the 2018 Western Japan heavy rain resulted in 232 casualties (224 dead and eight missing). These disasters were caused by localized torrential rain from the occurrence of linear precipitation bands. Many casualties of heavy-rain disasters are victims of sediment disasters, which is most likely among heavy rain-related natural disasters fatal for the victims.

The most effective means to save lives from sediment disasters is early evacuation. For early evacuation, the municipalities should anticipate the occurrence of sediment disasters at an early stage, issue evacuation information, and establish a system for residents to evacuate efficiently based on that information. In Japan, according to the Sediment Disaster Prevention Act, municipalities issue evacuation information based on sediment disaster alert information announced by prefectures and the Japan Meteorological Agency. However, in the case of short-duration heavy rainfall, sediment disaster alert information may not be announced timely. In addition, even if this information is announced, there often occur cases where evacuation information is not announced before the occurrence of a sediment disaster. 
Further, there is the reality that residents may not evacuate even if evacuation information is announced.

We conducted rainfall observation using real-time meteorological sensors for the purpose of supporting municipalities to issue early evacuation information by predicting the occurrence of sediment disasters due to short-duration heavy rainfall. In this paper, on the basis of the real-time rainfall-observation information from sensors installed in sediment disaster hazard zones, we present the current state of provision of information on sediment disaster risk. Then, we propose a method to use real-time rainfall-observation data from one site to estimate the short-duration heavy rainfall at another site and thus assess the risk of disaster occurrence.

\section{CURRENT STATUS AND ISSUES RELATED TO EVACUATION BASED ON THE SEDIMENT DISASTER PREVENTION LAW}

In the wake of the large-scale debris-flow disaster that occurred in Hiroshima Prefecture in 1999, the Sediment Disaster Prevention Act was enacted in 2001 to help in preventing future casualties in such hazard areas. In that disaster, there were 32 casualties (31 deaths and one missing) in Hiroshima City and Kure City, Hiroshima Prefecture. In order to save the lives of residents from sediment disasters, the law was formulated for the purpose of making clear areas where sediment disasters may occur, providing hazard information, establishing evacuation systems, and promoting non-structural measures such as restraint on new location of housing [1].

\subsection{Outline of the Sediment Disaster Prevention Act}

Prefectures designate the sediment disaster hazard zones as well as special hazard zones where disasters are anticipated to occur. On the basis of this designation, municipalities are obliged to make a sediment disaster hazard map and to make it public by providing it to residents. In the case of heavy rainfall, the prefectures jointly with the Japan Meteorological Agency announce earth and sand disaster-alert information, and on the basis of this information, municipalities issue evacuation information to residents in the identified areas and urge early evacuation. This law presupposes that community residents of the hazard zone establish a system of evacuation and evacuate voluntarily.

\subsection{Issues to be solved by the Sediment Disaster Prevention Act}

In Hiroshima Prefecture, a debris-flow disaster occurred in Hiroshima City in 2014, and there were 77 casualties. Although 13 years had passed since the enforcement of the law, the designation of sediment-related hazard zones had not been completed in the affected area. Even though such zones had been designated and published, 118 people died only in Hiroshima Prefecture because of the debris flow caused by the 2018 Western Japan heavyrain disaster. Fig. 1 shows the damage caused by debris flow in Yasuura-cho district, Kure City, Hiroshima Prefecture. The sediment disaster hazard map of the same area (Fig. 2) shows that all houses are within the range designated as the hazard zone. However, the hazard map is not very useful because there is no evacuation site shown in the area. Fig. 3 shows the damage caused by debris flow in the Kawasumi district, Kumano Town, Hiroshima Prefecture. The sediment disaster hazard map of the same area (Fig. 4) shows that debris flowed out from the valley via line No. 2, which was not judged to be a dangerous mountain stream. There are a lot of issues to be solved: Sediment disasters occur before the municipalities issue evacuation information, evacuations are not performed at night even if 
evacuation information has been issued, and sediment disasters also occur outside areas designated as hazard zones.

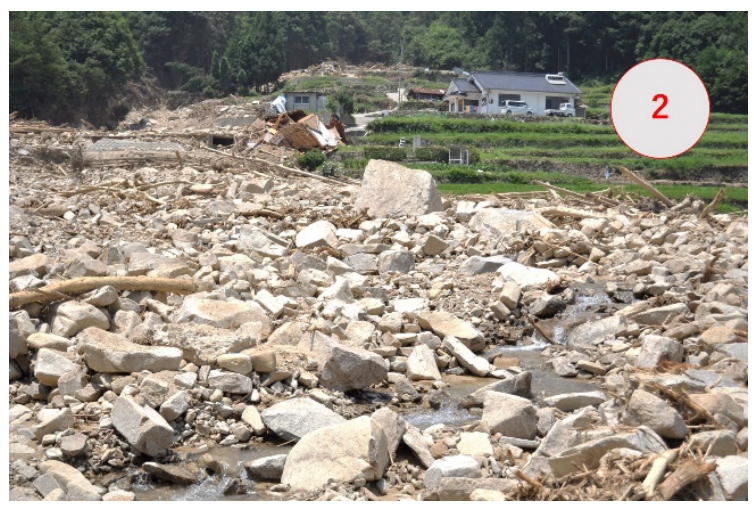

Figure 1: Debris flow occurred at Yasuura-cho due to the July 2018 western Japan heavy rain disaster.

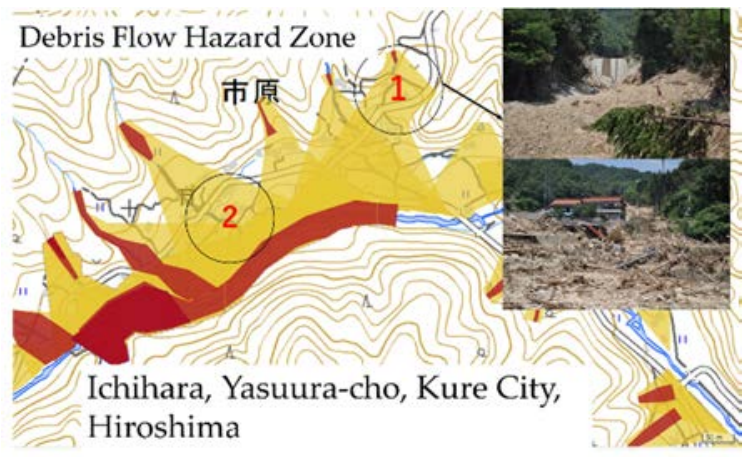

Figure 2: Sediment disaster hazard zone at Yasuura-cho, Kure City.

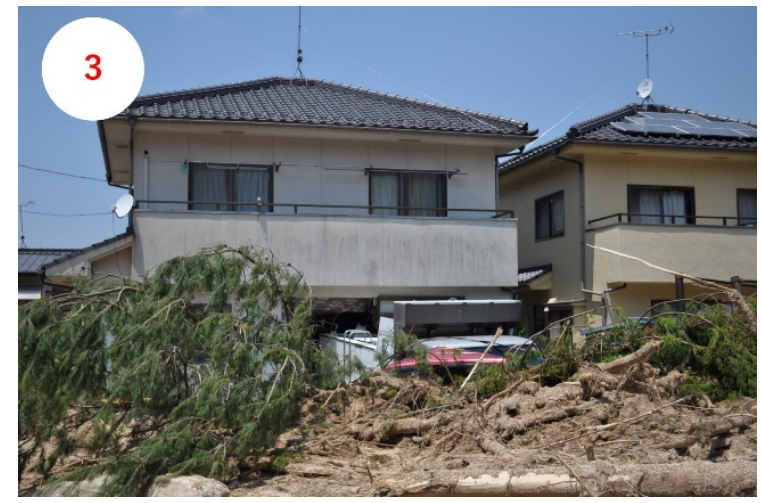

Figure 3: Damage due to debris flowed out from the valley line No. 2. 


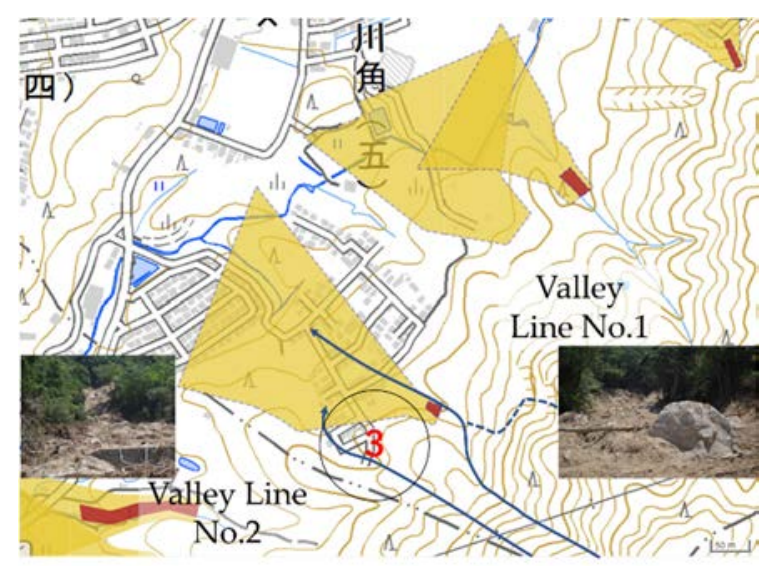

Figure 4: Sediment disaster hazard zone at Kawasumi, Kumano Town.

\subsection{Issues on sediment disaster alert information}

There are several issues involving evacuation based on sediment disaster alert information. First of all, the alert information is based on a critical line on a two-dimensional plot, with the soil-water index on the horizontal axis and $60 \mathrm{~min}$ accumulated rainfall on the vertical axis. When a point moves on this two-dimensional plane and the point is judged to have exceeded the critical line (after $2 \mathrm{~h}$ ), sediment disaster alert information is issued. Since the soil-water index is also calculated using $60 \mathrm{~min}$ accumulated rainfall as input, that is the most important parameter contributing to the sediment disaster alert information.

The $60 \mathrm{~min}$ accumulated rainfall is the amount of precipitation analyzed by the Automated Meteorological Data Acquisition System precipitation radar and corrected by rainfallobservation results acquired on the ground. Although the amount of precipitation is announced by the Japan Meteorological Agency at a resolution of $1 \mathrm{~km}$, the accuracy of the rainfall-observation points on the ground is only $\sim 10 \mathrm{~km}$. Thus, it is not suitable for local rainfall estimation. If the area where sediment disasters are likely to occur (designated hazard area) is in a mountainous area or on an alluvial fan along a mountain front, an updraft is likely to form, causing the amount of precipitation to be larger than that on the plain. It has been reported that five times the amount of rainfall in the plain has been observed in the adjacent mountainous area [2].

\section{EVALUATION OF SEDIMENT DISASTER OCCURRENCE USING REAL-TIME RAIN SENSORS}

The rain gauge used in this research is not a conventional tipping bucket. Rather, the rain sensors that we used measure the momentum generated by raindrops as an impact. It is known that a tipping-bucket rain gauge does not capture part of the precipitation owing to the Jevons effect, whereby air flow is disturbed near the receiver. Strong wind from the side also reduces the capture rate of rain in the receiver. However, we put more emphasis on the fact that a tipping-bucket rain gauge lacks real-time performance and is not suitable for short-duration heavy-rain measurements, as it is a measurement method that depends on temporarily storing rain. For example, when the rainfall that fell in 30 or $10 \mathrm{~min}$ is measured, it is a problem that a 30- or 10-min delay would occur in the evacuation judgment. In addition, to predict the 
occurrence of sediment disasters, we consider rainfall information at specific points in the hazard zone to be essential.

\subsection{Precipitation observation using real-time rain sensor}

We installed five weather sensors (Fig. 5) in Nishikatsura Town, Yamanashi Prefecture, for observation and used the data from it to provide information to municipalities in support of their evacuation judgment for sediment disasters. Nishikatsura Town requested that weather sensors be installed at five locations: two in the sediment disaster hazard zone (debris-flow hazard area), one on the roof of Nishikatsura Town Hall, and two on the bank of the Katsura River that flows east and west of the center of the town. A screenshot (Fig. 5) from the rainfall-observation website jointly implemented by the authors and Nishikatsura Town shows the actual observation information in the case of 2018 Typhoon No. 12. The number in the circle shows the accumulated rainfall for the previous $72 \mathrm{~h}$, and it can be seen from the five observation points in the north and south near the mountainous area that there was already $>200 \mathrm{~mm}$ of precipitation. By contrast, there were two to four riverside stations, and $<120 \mathrm{~mm}$ had accumulated at two of those stations. Thus, in that typhoon, at least $66 \%$ more rainfall was observed in the sediment disaster hazard zones near mountains as on the floodplain. Sediment disaster alert information is provided for each municipality, and because the mesh resolution of the information is $5 \mathrm{~km}$, Nishikatsura Town fits completely into one $5-\mathrm{km}$ mesh, and uniform risk of sediment disaster occurrence is calculated in Nishikatsura Town regardless of the mountainous area and the flat area. However, as shown in the figure, it was also confirmed that the difference in rainfall amount can be double depending on location even in Nishikatsura Town [3].

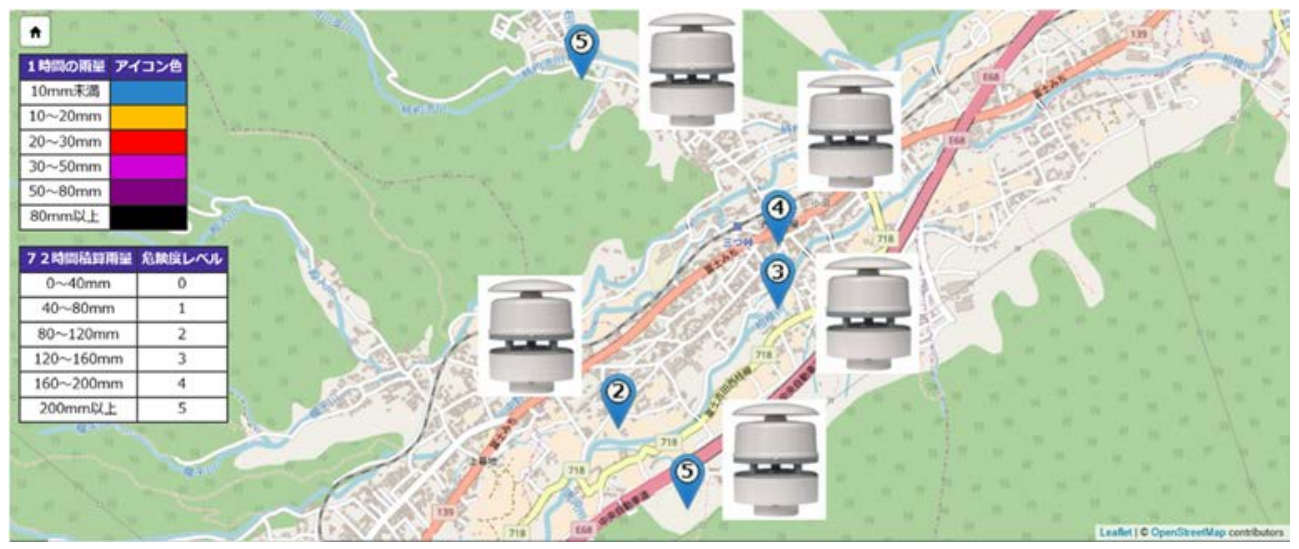

Figure 5: Sediment disaster occurrence risk information evaluated by rainfall observation using real time rain sensors (Typhoon No. 12, 29 July 2018) [3].

As the first step to evaluate the risk of sediment disaster occurrence, we created the abovementioned website that shows real-time rainfall intensity (in $\mathrm{mm} / \mathrm{h}$ ) and the current status of accumulated rainfall in Nishikatsura Town at a glance (Fig. 5). This rainfall intensity is calculated by converting 1-min rainfall observed by the sensor into 60 -min rainfall. The integrated rainfall (in $\mathrm{mm}$ ) is the cumulative amount over the prior $72 \mathrm{~h}$, which determines the risk of sediment disaster due to long-duration rain, and the 72-h threshold for issuing 
evacuation information was set at $200 \mathrm{~mm}$. However, the occurrence of debris flow is predicted based on rainfall intensity, and evacuation information is issued even if the accumulated rainfall has not reached $200 \mathrm{~mm}$. In addition to the sediment disaster alert information jointly announced by Yamanashi Prefecture and the Japan Meteorological Agency, Nishikatsura Town decided to issue evacuation information using the website that we created. As a result, Nishikatsura Town is able to issue evacuation information at the earliest possible time for Yamanashi Prefecture.

\subsection{Verification of real time rain sensor}

The second observation point from the top of Fig. 5 is the roof of the Nishikatsura Town Hall. Here Nishikatsura Town has also installed a tipping-bucket-type rain gauge to observe rainfall. When the real-time rainfall sensor was first installed there, the rainfall data from the sensor were compared to the rainfall accumulated by the tipping-bucket rain gauge to verify the observation accuracy of the real-time rainfall sensor. We found that a good correlation is obtained between the two observation results (Fig. 6(a)), if a correction is applied by taking into consideration the rainfall capture rate of the tipping-bucket rain gauge and using the wind direction and wind recorded by the real-time weather sensor.

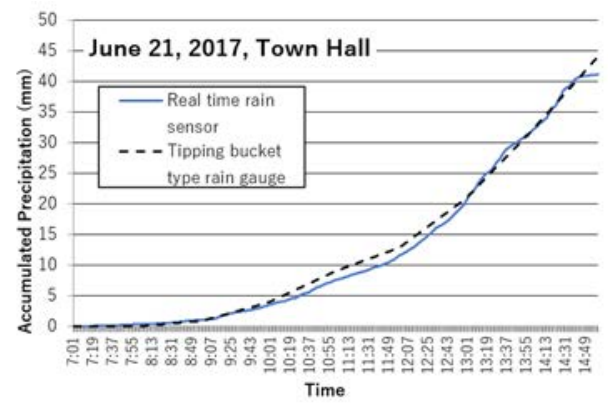

(a)

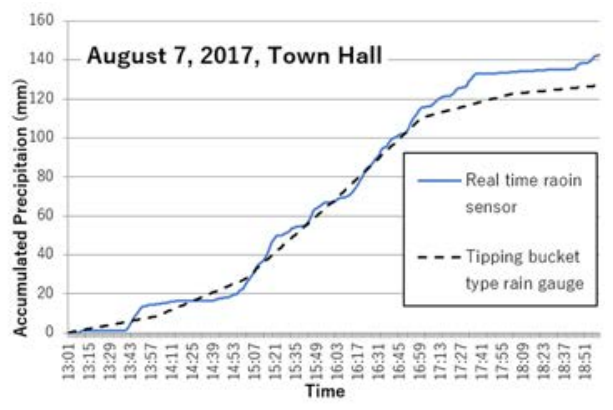

(b)

Figure 6: Comparison of accumulated rainfall observed by the real-time rain sensor with that observed by a tipping bucket type rain gauge on the roof of Nishikatsura Town Hall. (a) Rain event on 21 June 2017; and (b) Rain event on 7 August 2017.

Since the tipping-bucket rain gauge is installed on the roof only $50 \mathrm{~cm}$ from the outer wall of the building, it is greatly affected by air flow and by structures on the roof. The structures act as obstacles, further reducing the rain-capture rate, depending on wind direction and speed. The influence becomes larger in strong wind events such as a typhoon. We compared the corrected rainfall of the tipping-bucket rain gauge with the observed rainfall divided by the capture rate and with the observed rainfall of a real-time rain sensor, taking into consideration the influence of the roof structure at the time of 2018 Typhoon No. 12 (Fig. 6(b)). Thus, we were able to verify that the real-time rain sensor is effective even in heavy rainfall accompanied by wind, although there was a rainfall event in which the cumulative observed rainfall of the tipping-bucket type rain gauge is more than $20 \%$ smaller than that of the realtime rain sensor when the influence of wind and buildings is extremely large at the time of a typhoon with extremely strong wind. 


\subsection{Periodic characteristics of short-duration heavy rain}

During the past two years' observation period, sediment disasters did not occur in Nishikatsura Town, but debris flows occurred in nearby communities. The rainfall-intensity time history for the short-duration heavy rain observed in Nishikatsura Town, when it caused the debris flows in Ootsuki City $20 \mathrm{~km}$ away from Nishikatsura Town, was displayed at 1-min intervals, we found that there were peaks with a predominant period of 10-20 min. Fig. 7 shows a short-duration heavy rainfall event of 8 August 2018. Others also have noted such periodic characteristics from the measurement of rainfall intensity at 1-min intervals. Yamada et al. reported a similar rainfall pattern by observation with a special rain gauge that can monitor rainfall at 1-min intervals [2]. The 1-min-interval observations revealed that some instantaneous high-intensity rain had not been observed in short-duration heavy rain recorded at longer intervals. Because such high-intensity heavy rainfall may cause sediment runoff from the top layer of slopes and trigger debris flow, this phenomenon must also be considered a mechanism of sediment disaster occurrence.

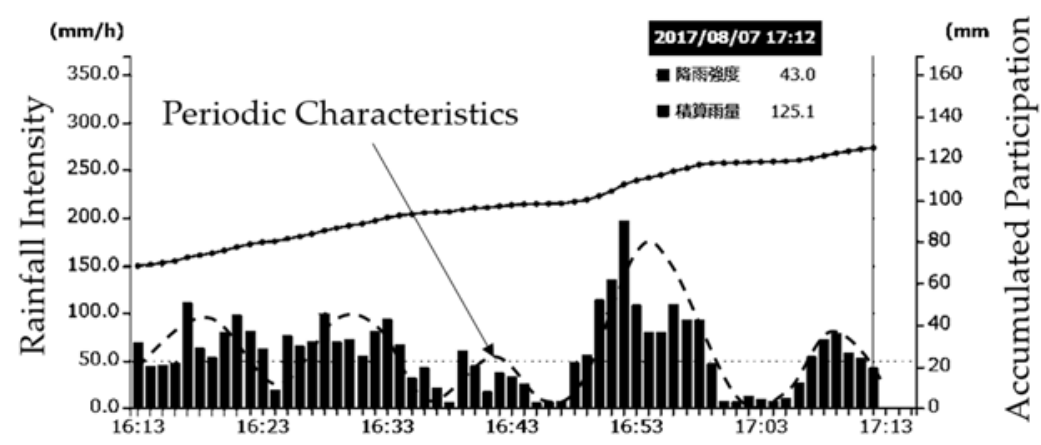

Figure 7: Periodic characteristics of rainfall intensity observed by real-time rain sensor.

By calculating a moving-average of rainfall-intensity time-series data and then subtracting it from the time-series data, temporal variation of rainfall intensity can be obtained. The lowpass filter can be adjusted by changing the width of the moving average. We determined the temporal variation using a width of $5 \mathrm{~min}$, which yielded five data points. Fig. 8 is time series data of the rainfall intensity on 7 August 2017, and Fig. 9 is a result of calculating the moving average of rainfall intensity data shown in Fig. 8. Fig. 10 shows the temporal variation of rainfall intensity data shown in Fig. 8. Fourier spectrum of the temporal variation is illustrated in Fig. 11, where periodic characteristics can be clearly seen in the variation of rainfall intensity, with a predominant period of 15-20 min.

\section{PREDICTION OF FUTURE RAINFALL USING AMPLITUDE AND PHASE CHARACTERISICS OF RAINFALL INTENSIY TIME HISTORY}

\subsection{Method of prediction of future rainfall}

In earthquake engineering, there is a method of simulating earthquake motion fitted to a response-spectrum design using the phase of strong motion [4]. By this method, input earthquake motions of various phases are designed using strong-motion records of large earthquakes observed in various locations. We propose a method to forecast rainfall at a 


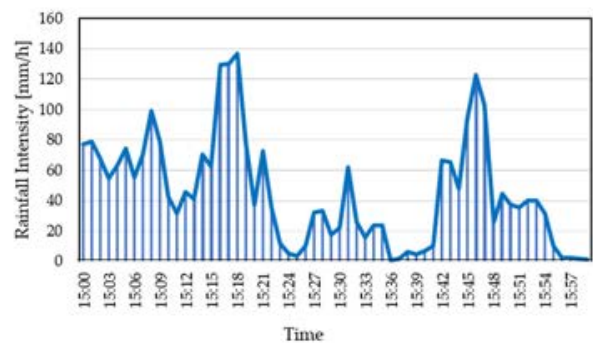

Figure 8: Rainfall intensity time history.

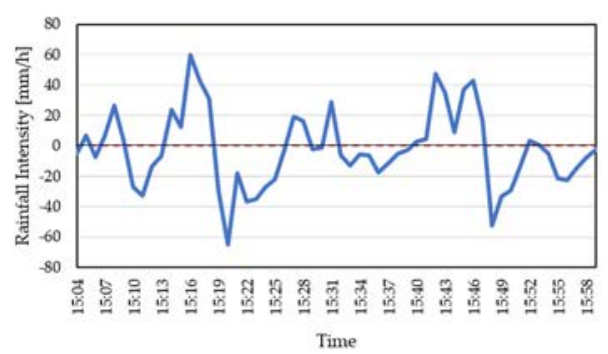

Figure 10: Temporal variation.

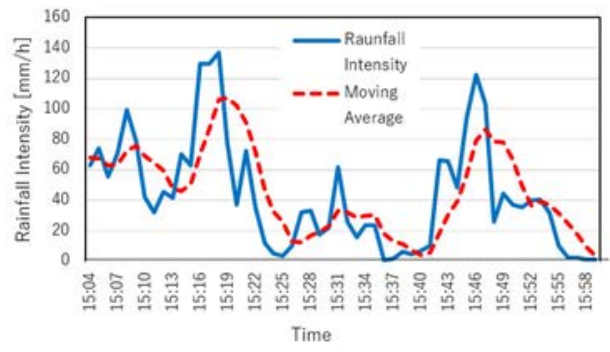

Figure 9: Moving average time-series.

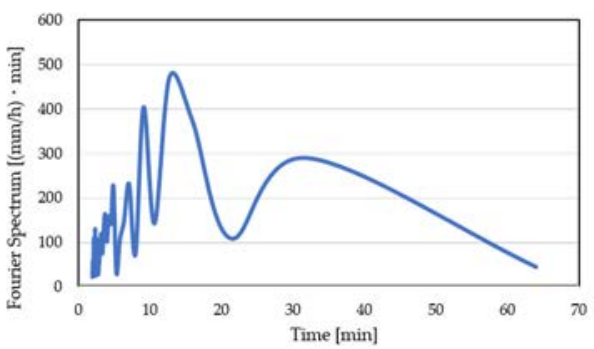

Figure 11: Fourier spectrum of the variation.

certain observation point by applying essentially the same method. In this case, when a rain cloud that causes heavy rainfall moves from observation point $\mathrm{A}$ to observation point $\mathrm{B}$ and when a high correlation can be observed between the rainfall-intensity time histories at the two observation points, it is possible to predict future rainfall at observation point $\mathrm{B}$ according to the following procedure, using the phase characteristics at observation point $\mathrm{A}$ and amplitude characteristics at observation point $\mathrm{B}$.

1. Determine the variation component of rainfall intensity time history at both observation points.

2. Calculate the time difference $T_{d}$ (in minutes) between observation points $A$ and $B$ from the cross-correlation function of both observation points.

3. Perform Fourier transform of the variation component at both observation points to obtain the Fourier amplitude and phase angle.

4. Using the amplitude characteristics (amplitude spectrum) of the variation component at observation point $\mathrm{B}$ and the phase characteristics (phase angle) of the variation component at observation point $\mathrm{A}$, create the Fourier coefficient $C_{k}$ as shown in eqn (1):

$$
C_{k}=\frac{F_{k}}{T}\left(\cos \varphi_{k}+i \sin \varphi_{k}\right),
$$

where, $C_{k}$ denotes Fourier coefficient of the predicted temporal variation $x_{m}, F_{k}$ the Fourier amplitude spectrum of the k-th element of the temporal variation at Point B, 
$T$ time duration of the temporal variation and $\varphi_{k}$ the phase angle of the k-th element of the temporal deviation at Point A.

5. Determine a new simulated time-series component of the variation $x_{m}$ by performing an inverse Fourier transform of the Fourier coefficients in eqn (1):

$$
x_{m}=\sum_{k=0}^{N-1} C_{k} e^{i\left(\frac{2 \pi k m}{N}\right)} \mathrm{m}=0,1,2, \ldots, \mathrm{N}-1 .
$$

6. Determine the time series of simulated rainfall intensity by summing the timeseries component of the simulated variation and the moving average at observation point B.

7. Use the time component $T_{d}$ from the tail end of the simulated rainfall-intensity time series for the future-prediction time component $T_{d}$ at observation point $\mathrm{B}$.

\subsection{Verification of the method}

Using the above proposed method, we developed the rainfall-prediction program and performed rainfall forecasting using rainfall-intensity data from two observation points observed on 23 October 2017 in Nishikatsura Town. Rainfall intensity after 0:20 was forecast using the Fourier amplitude spectrum of the time-series component of the variation from 23:20 at the Citizen's Ground observation station (Point B, the southernmost station) and the phase angle of the time-series component of the variation from 0:20 at Irita observation station (Point A, the northernmost station). Fig. 12 compares the predicted rainfall intensity (red line) with the actual observed rainfall intensity (blue line). Assuming that the phase difference between the two points was $4.5 \mathrm{~h}$, we carried out the above forecast of rainfall intensity. Because the actual distance between the two observation points is about $3 \mathrm{~km}$ and the phase difference (Td) is only $2 \mathrm{~min}$, it is natural that they agree well. However, the validity of the proposed method was demonstrated. Fig. 13 compares the predicted cumulative precipitation (red line) with the actual observed cumulative precipitation (blue line). Similar comparisons are made with other rainfall events as shown in Figs 14 and 15.

When the distance between two observation stations exceeds the range of continuous movement of the rain cloud, such as when a cumulonimbus cloud occurs locally, overestimation or under-estimation of rainfall occurs. For accurate early warning, therefore, it is

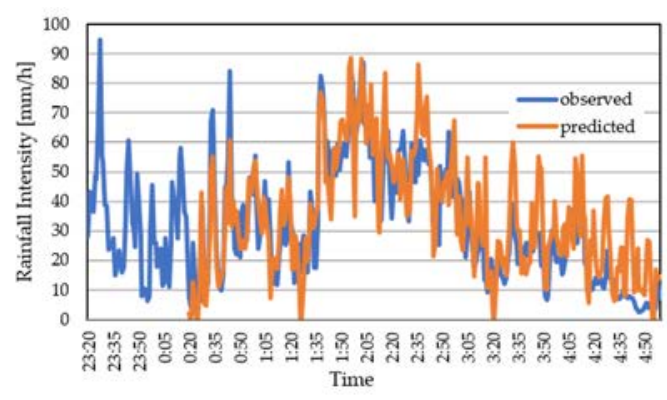

Figure 12: Comparison of observed and predicted rainfall intensity time history (23 October 2017).

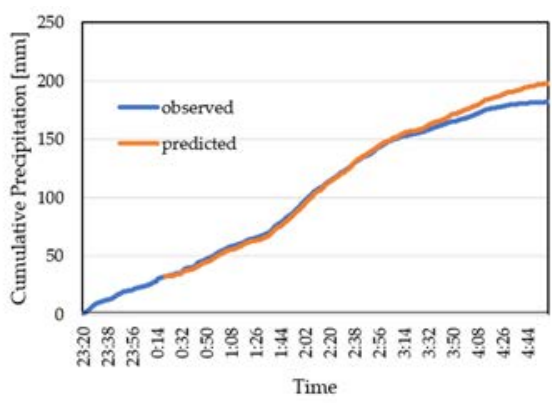

Figure 13: Comparison of observed and predicted values in cumulative precipitation $(23$ October 2017). 


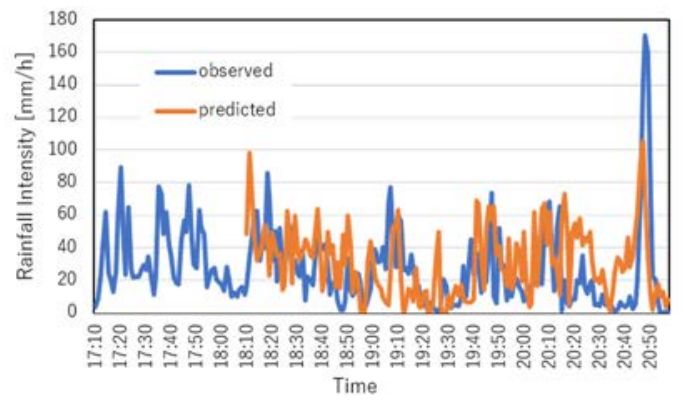

Figure 14: Comparison of observed and predicted rainfall intensity time history (28 July 2018).

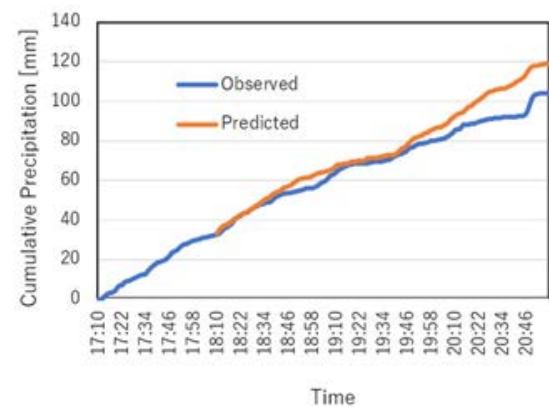

Figure 15: Comparison of observed and predicted values in cumulative precipitation (28 July 2018).

necessary to build a system that predicts rainfall by arranging rainfall sensors continuously so that movement of not only wide-area rain clouds but also local rain clouds can be taken into consideration.

\section{CONCLUSIONS}

By installing a real-time rainfall sensor in a sediment disaster hazard zone, it is possible to evaluate the sediment-related-disaster risk at specific points and in real time with high accuracy. Furthermore, we showed that it will be possible to forecast rainfall and sediment disaster occurrence by evaluating autocorrelation and cross-correlation of rainfall intensity between rainfall-observation stations in real time. When rainfall observation is carried out at specific points and in real time in the sediment disaster hazard zone by adjacent municipalities, it is possible to forecast rainfall of $\sim 1 \mathrm{~h}$ using the cross-correlation between observation points regardless of municipal boundaries. The authors have proposed a method of forecasting rainfall, focusing on the periodic characteristics of short-duration heavy rainfall. It seems possible to forecast rainfall and sediment disasters by applying machine learning, even in cases where the periodic characteristics are not remarkable and are irregular.

\section{REFERENCES}

[1] Disaster Management Bureau, Flood and Sediment Disaster, Cabinet Office, Japan, 2018.

[2] Nagata, Y., Yoshimi, K., Nagashima, K. \& Yamada, T., A study on the short-term characteristics of rainfall phenomenon. Proceedings of Japan Society of Civil Engineers, G, 71(5), pp. I277-I282, 2015. (In Japanese.)

[3] Suzuki, T., Disaster Management and Engineering, Riko Tosho Publishing Company, pp. 135-136, 2019. (In Japanese.)

[4] Suzuki, T., Adachi, Y.\& Tanaka, M., Application of microtremor measurement to the estimation of earthquake ground motions in Kushiro City during the Kushiro-oki earthquake of 15 January 1993. Earthquake Engineering and Structural Dynamics, 24, pp. 595-613, 1995. 